\title{
Medicina Universitaria: Past, present, and future
}

\author{
Edelmiro Pérez-Rodríguez and Félix Vilchez-Cavazos* \\ School of Medicine, "Dr. José Eleuterio González", University Hospital, Universidad Autónoma de Nuevo León, Monterrey, Nuevo Leon, Mexico
}

The three pillars on which the School of Medicine of the Autonomous University of Nuevo León is based are healthcare, teaching, and research. During the last decade, the consolidation in the research area has been very important. This is supported by the number of professors in the National System of Researchers, publications in international journals, patents, and utility models.

An essential part of the creation of knowledge is its dissemination. If knowledge is not transmitted beyond a laboratory, an operating room or an office, it has little use. One of our medical school tasks is to find effective means for the dissemination of knowledge.

The School of Medicine of the Autonomous University of Nuevo León is proud to celebrate the $50^{\text {th }}$ anniversary of its journal "Medicina Universitaria," which was published for the $1^{\text {st }}$ time in January 1970.

Under the vision of a great Professor from our School, Dr. Álvaro Gómez Leal, at the beginning of the seventies of the last century, he laid the foundations for the journal "Medicina Universitaria" to celebrate 50 years since its first publication.

Our journal has been the platform for researchers, teachers, students, and health professionals from our university, Mexico, and internationally to disseminate their scientific activity.

During the last two decades, the journal "Medicina Universitaria" has been published quarterly, four issues a year, to spread new medical knowledge in the scientific community. At present, our journal is published in English to have a worldwide reach. Under the hand of an international publisher, it has the goal of consolidating its presence outside of Mexico.

Within the celebrations of this anniversary in this issue, we show the reprint of the cover of the first edition of "Medicina Universitaria."

Our most sincere congratulations to the entire team that makes possible the journal's publication quarter by quarter, where their scientific capacity, perseverance, leadership, and love for our institution are demonstrated.

\section{Correspondence:}

*Félix Vilchez Cavazos

E-mail: vilchez.doctor@gmail.com
Date of reception: $25-11-2020$

Date of acceptance: 30-11-2020 DOI: 10.24875/RMU.M20000055
Available online: $24-12-2020$

Medicina Universitaria. 2020;22(4):142-142 www.medicinauniversitaria.org

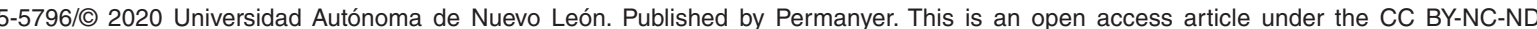
license (http://creativecommons.org/licenses/by-nc-nd/4.0/). 